\title{
DA GRAVATA AZUL À MAMADEIRA OBSCENA: NOTAS SOBRE A CRÍTICA LITERÁRIA HOJE
}

\author{
FROM A BLUE TIE TO AN OBSCENE BABY BOTTLE: NOTES ON \\ CURRENT LITERARY CRITICISM
}

Tauan TINTI*

\begin{abstract}
Resumo: O presente ensaio busca apresentar o argumento geral do livro recente de Joseph North, Literary Criticism - A Concise Political History, ligado à disputa entre o que autor chama de "paradigma crítico" e "paradigma historicista-contextualista" ao longo da crítica literária de língua inglesa, para em um segundo momento tentar extrapolar parte da discussão para o contexto brasileiro, bem como chamar a atenção para desenvolvimentos na história da arte em geral a partir do modernismo que foram deixados de lado por North. Para tanto, o ensaio reconstrói, antes de apresentar o argumento de North, algumas das ideias do filósofo Arthur C. Danto que levarão, ao final do texto, a considerações sobre as possibilidades de recuperação do paradigma crítico de que fala North no contexto de monopólio da indústria cultural sobre a educação da sensibilidade contemporânea.
\end{abstract}

Palavras-chave: Joseph North. Sentido e intenção. Educação estética. Indústria Cultural.

Abstract: The essay presents the general argument of Joseph North's recent book Literary CriticismA Concise Political History, related to a dispute between what the author calls the "critical" and the "historicist-contextualist" paradigms throughout English literary criticism. It has a twofold objective: it attempts to extrapolate some of North's claims to the Brazilian context and draws attention to artistic developments from Modernism onwards that were left aside by North. Before presenting North's argument, it revisits some of Arthur C. Danto's ideas on the nature of meaning in art that will lead to some considerations on the possibilities of recovering the critical paradigm discussed by North in the context of the monopoly that the Culture Industry seems to hold over the contemporary education of the senses.

Keywords: Joseph North. Meaning and Intention. Aesthetic Education. Culture Industry.

1.

Vista pela TV em um começo de madrugada perdida, a mistura de despropósito com burocracia sugere um esporte inventado por Kafka, disfarçado sob o nome de salto ornamental. Um dos atletas - digamos, Joseph K. ou algo assim - se prepara na plataforma para o mergulho enquanto o comentarista da Sportv anuncia o coeficiente de dificuldade do salto (!), que descubro depois variar entre 1,2 e 3,8. Algumas piruetas e cerca de nenhum segundo depois, seu corpo entra quase reto na água, mas o mesmo comentarista menciona que K. espalhou água

\footnotetext{
* Pós-doutorando no Programa de Pós-Graduação em Letras da Universidade Federal da Paraíba (UFPB). Doutorado em Teoria e História Literária pela Universidade Estadual de Campinas (UNICAMP). E-mail: tauantinti@gmail.com. ORCID https://orcid.org/0000-0003-3600-230X
} 
um pouco demais ao entrar na piscina, o que certamente irá prejudicar a avaliação de sua performance. Dito e feito: o painel de juízes, que dizem não conversarem entre si, apresenta notas variando entre 7 e 8 (“culpado!", não se sabe bem de quê). A mais alta e a mais baixa são cortadas do cálculo da média, que é por sua vez multiplicada pelo tal coeficiente de dificuldade, e o número alcançado na planilha tem só a mais vaga relação com qualquer beleza que meus olhos leigos tenham sido capazes de perceber. Mas, claro, como lembra um escritor como David Foster Wallace num de seus melhores ensaios, dedicado ao tenista Roger Federer (WALLACE, 2012), não é só de beleza que se trata nessas coisas, ainda que o "ornamental” do salto pudesse guiar a percepção nesse sentido (como, aliás, o "artística" da ginástica de alguma outra madrugada): há também a exibição de virtuosismo, do corpo humano levado ao limite do possível - ou melhor, como escreve Wallace sobre a visão de Federer em um lance de gênio, da "reconciliação [vicária] dos seres humanos com o fato de terem um corpo". No argumento do ensaio, a "beleza humana" em questão nos esportes competitivos seria de apelo universal, desvinculada de normas culturais ou convenções de todo tipo - e, se exibi-la ou encontrá-la não é de fato propriamente neles a meta, não deixam de ser mesmo assim um terreno privilegiado para sua irrupção (Wallace, uma última vez: a relação entre beleza e esporte seria mais ou menos aquela entre a coragem e a guerra). Mas de volta mais um pouco àqueles atletas um tanto absurdos: Joseph K. sai da piscina olímpica rumo ao chuveiro enquanto Gregor Samsa se posiciona na plataforma de salto, e seus rodopios serão descritos numa linguagem técnica que pouco diz a um não-iniciado como eu - de tudo, só entendo que enfrentam a gravidade menos em busca do voo do que de uma brecha de queda menos súbita - menos livre -, mas isso nada diz de suas notas. Saltos e respingos depois, eis Joseph K. lá em cima de novo, talvez pela terceira vez: em um requinte burocrático final comum a esportes desse tipo, cada atleta deve apresentar seus mergulhos em três vias (minto: são quatro), devidamente preenchidas na vertical e com o mínimo de água espalhada possível.

Arthur C. Danto, o renomado crítico e filósofo da arte, e que é provavelmente mais conhecido por sua verdadeira obsessão pelas implicações artísticas das obras conceituais de Andy Warhol (a Brillo Box, as pinturas das Latas de Sopa Campbell's), costumava dizer que, mais ou menos do Expressionismo Abstrato em diante, ficou cada vez mais comum que as obras de arte produzidas sejam menos imediatamente interessantes - atraentes, estimulantes - do que as interpretações feitas pelos críticos a partir delas. Em O abuso da beleza (DANTO, 2015), Danto vai além, e chega a defender que, em casos especialmente complicados como o do urinol de Duchamp ou da Brillo Box de Warhol, aquilo que poderia ser imediatamente estimulante nas obras (formato, cores etc.) simplesmente não interessa: qualquer beleza nelas disponível seria 
apenas acidental, externa ao significado das obras e fruto, digamos, das condições de produção de seus locais de origem (as motivações comerciais no design de penicos ou de embalagens etc.). Ou, como ele mesmo formula: “[n]a verdade, não sei o que é a estética da Brillo Box de Warhol, se é que ela tem alguma. Assim como a Fonte, ela é essencialmente uma obra conceitual" (DANTO, 2015, p. 14) - que diz respeito no argumento de Danto à diferença, de certo ângulo agora irrelevante, entre arte e não-arte. Se é que ela tem alguma: guardadas as proporções, a relação entre a estética da Brillo Box e seu conceito não deixa de ser parecida, ao menos aos olhos de um leigo, com aquela entre a estética do salto ornamental do "Joseph K." do parágrafo anterior e a nota que aparecia na planilha dos juízes - que, claro, não é exatamente seu conceito em sentido filosófico, mas salvo engano, saltos ornamentais também não costumam ser objeto de interpretação. De outro lado, como acabei de registrar, essa relação só se deixa formular como não-relação caso considerada do ponto de vista de um leigo, já que os juízes certamente se baseiam em detalhes tanto sensíveis quanto bastante convencionados para atribuírem suas notas aos saltos - algo que é reforçado pelo fato de o crítico da Sportv, claramente especializado naquilo, ter acertado a região geral das notas da grande maioria deles (e eu não, nem de longe).

Já em A transfiguração do lugar-comum (Idem, 2005), Arthur Danto leva totalmente a sério uma discussão que a princípio parece fazer mais sentido em mesas de bar ou almoços de famílias de estudantes de humanas do que em trabalhos filosóficos. Não acho que seja um exagero dizer que a maioria de nós, estudantes e/ou professores de literatura, já ouviu ou poderia ouvir (ou até dizer), diante de algum quadro ou escultura de museu sem apuro técnico evidente (pensem no famoso "anjo da história" de Paul Klee, e em parte também de Walter Benjamin), alguma variação de "até o meu filho faz isso" (ou sobrinho, irmã mais nova etc.). Pois bem: Danto inventa então uma obra desconhecida da fase azul de Picasso, La Cravate, que não passaria de uma gravata pintada inteira de azul. Na sequência, inventa também o filho de alguém, que de fato pintou toda de azul uma outra gravata, sem qualquer relação com a "obscura" obra de Picasso, mas ainda assim dela indiferenciável, mesmo nos mínimos detalhes, por alguma coincidência quase mística. Duas gravatas idênticas, então, num experimento de pensamento que encara de frente o mais leigo dos protestos ("até o meu filho faz isso"), e que no fim das contas pouco tem de ingênuo: diante delas, Danto irá dizer que, bom, as gravatas podem até ser iguais, totalmente iguais, inclusive, mas ainda assim uma delas é uma obra de arte - menor, diga-se de passagem - , enquanto a outra não é - e isso mesmo no caso de um acidente bizarro do destino (que, pasmem, Danto de fato cogita e leva adiante) resultando numa gravata trocada pela outra num museu qualquer. A solução dada pelo filósofo para o aparente 
disparate do caso das duas gravatas é, em linhas gerais (DANTO, 2005), a seguinte: em primeiro lugar, ainda que qualquer ação no mundo tenha sempre em última instância uma ou mais causas determinantes (o garoto pintou uma gravata do pai para irritá-lo, Picasso estava atrás de uns trocados a mais), apenas certos tipos de objetos - notadamente as obras de arte - possuem também um assunto ou significado ${ }^{1}$, que cabe à interpretação encontrar e formular por meio de argumentos que possam ser confrontados com outros e assim por diante. Dito em termos simples, o garoto pode até ter pintado a gravata para irritar seu pai, mas sua gravata pintada de azul não é sobre irritar o pai, já que ela não é, afinal de contas, sobre nada. De outro lado, $L a$ Cravate pode ter sido criada por Picasso sem nenhum assunto em mente, mas mesmo isso se pode converter em seu assunto, indo de ser sobre uma recusa a qualquer tema para as artes plásticas, bem ao gosto de um Clement Greenberg, a ser sobre o desmascaramento dos interesses materiais volta e meia grosseiros da parte dos artistas - ou sobre qualquer outra coisa.

Ou seja, em primeiro lugar, obras precisam ser sobre algo - com efeito, como insiste seguidamente o crítico Fabio Durão em seu livro mais recente (DURÃO, 2019), o enunciado interpretativo fundamental é precisamente "[a obra] X é [ou significa] Y”; dito um pouco melhor, é necessária uma intenção significante para que elas possam de fato significar algo (mesmo que algo alheio, diferente ou mesmo oposto à tal intenção) ${ }^{2}$. Em segundo lugar, a simples possibilidade de alçar uma mera gravata pintada de azul ao estatuto de obra de arte não é um gesto neutro ou que sempre esteve disponível, mas, ao contrário, depende fundamentalmente tanto de certos desenvolvimentos da história da arte (por sua vez ligados à história em sentido amplo) quanto de que essa história tenha sido em alguma medida internalizada pelo indivíduo que pinta a tal gravata de azul - algo que seria impossível (ou ao menos muito, muito improvável) para o garoto do parágrafo anterior, perdido em seus eventuais conflitos edipianos $^{3}$. Ainda em torno da gravata hipotética de Picasso, Danto cogita uma terceira

\footnotetext{
${ }^{1}$ Em inglês, subject. Sobre isso, vale lembrar de passagem a distinção entre conteúdo [content $]$ e tema ou assunto [subject matter] feita por Clement Greenberg, crítico de arte anterior a Danto: "toda obra de arte precisa possuir um conteúdo [content], mas um assunto [subject matter] é algo que o artista pode ou não ter em mente quando está de fato produzindo". Para Greenberg, toda a pintura seria sempre e em última instância sobre a resistência da tela à pressão do pincel com tinta, e tudo o mais nos quadros (temas figurativos etc.) estaria subordinado ao problema do meio, que é, por fim, específico de cada arte. Cf. GREENBERG, Clement. Towards a Newer Laokoon. In: Collected Essays, vol. I. Chicago: Chicago University Press, 1986.

${ }^{2}$ Nesse sentido, aliás, vale mencionar o argumento de Nicholas Brown no capítulo introdutório de seu Autonomy de que, nessa lógica, uma mercadoria cultural "pura" - um exemplo recorrente de Brown é o Avatar de James Cameron - também não seria dotada de um significado imanente, já que, por ser feita com o propósito definido e único de apelar para os gostos dos consumidores, são apenas esses gostos que são passíveis de explicação ("por que diabos as pessoas querem ver seios em fêmeas azuis gigantes de uma espécie não-mamífera?"), mas não de interpretação. Digamos assim: Avatar foi feito para ganhar o máximo de dinheiro possível, mas não é sobre ganhar o máximo de dinheiro possível, já que ele não é, afinal de contas, sobre nada. Cf. BROWN, Nicholas. Autonomy. Durham, NC: Duke University Press, 2019, esp. p. 1-27.

${ }^{3}$ [Nota sobre o ensaio do Schwarz sobre a Helena Morley?]
} 
interpretação, que faz dessa obra de faz-de-conta um comentário entre irônico e agressivo sobre a polêmica arcana em torno do papel da pincelada no Expressionismo Abstrato em voga na época (nesse caso, La Cravate teria sido pintada nos anos 1950). "O ponto principal desse argumento", como resume Danto, "é que uma pessoa não familiarizada com a metafísica da pincelada não se daria conta do significado da aplicação uniforme de tinta em La Cravate" (DANTO, 2005, p. 95). Até meu filho faz isso: sim, mas mesmo ao fazer a mesma coisa, ele acaba mesmo é fazendo outra. E, mais do que isso: ao pai da criança, se ele não é um iniciado na "metafísica da pincelada", é vetado o acesso ao sentido artístico da gravata no museu, que se torna assim, para ele, virtualmente idêntica à gravata sem sentido do filho, o que leva de volta ao ponto de partida da história toda. Em suma, o sentido da obra - melhor dizendo, a própria possibilidade de que uma obra faça sentido - depende das relações que ela estabelece com uma tradição na qual se insere e com a qual dialoga - e, para que isso seja possível, é necessário que essa tradição esteja em alguma medida disponível, tanto para quem cria quanto para quem interpreta. Com isso, chegamos ao que interessa mais de perto.

2.

No final de 2017, o crítico literário Joseph North publicou um pequeno - e, a meu ver, valioso - livro que parece ter, ao menos por enquanto, passado despercebido por aqui. Literary Criticism: A Concise Political History (NORTH, 2017), apesar do título um tanto despretensioso, apresenta uma tese das mais ousadas, que vou tentar resumir nesses próximos parágrafos. A história da crítica literária, ao menos nos países de língua inglesa, teria sido marcada desde sua consolidação como disciplina acadêmica, no começo do século XX, pela convivência e disputa de "acadêmicos" literários (scholars, termo difícil de traduzir em sentido preciso) e "críticos" literários em sentido convencional - como escreve North, trata-se da diferença chave "entre aqueles que tratavam o estudo da literatura como um meio para analisar a cultura e aqueles que tratavam o estudo da literatura como uma oportunidade para intervir na cultura" (Ibidem, p. 1-2). Dessa oposição central se desdobram todas as outras, ramificadas em diferentes correntes teóricas, e a tendência geral, por motivos bons como também ruins, foi a de associar aos representantes desse paradigma "crítico" posições conservadoras, enquanto a tendência de fundo do paradigma "scholar" (que depois North vai chamar de "historicistacontextualista") seria vista como progressista em sentido amplo. Após um período de relativa hegemonia do paradigma crítico, encabeçado pela Nova Crítica nos Estados Unidos e por F. R. Leavis e a revista Scrutiny (“escrutínio”, exame minucioso) na Inglaterra, em meados dos anos 
1970 e início dos 80, os críticos acabaram suplantados de vez pelos scholars, naquilo que foi e é até hoje visto como uma "vitória da esquerda sobre o elitismo da crítica de meados do século" (NORTH, 2017, p. 3), outrora voltada para um cânone reduzido e preocupada em geral apenas com obras de valor reconhecido e com a educação da sensibilidade e do gosto: como sintetiza North, “[p]ara bem ou para mal, metade da disciplina simplesmente sumiu” (Ibidem, p. 2). Na verdade, na avaliação de North, o sumiço foi no fim das contas para mal, mesmo: sem meias palavras, ele escreve já de saída, em plena página 3 do livro, que a aparência de vitória das forças progressistas "foi sintomática de um recuo mais amplo da esquerda durante o período neoliberal, e foi, portanto, uma pequena parte de uma vitória mais geral da direita" (Ibidem, p. 3). Para evitar mal-entendidos: se algumas páginas depois ele irá considerar os avanços progressistas na disciplina (abertura do cânone, desconfiança do lado transcendente da literatura, atenção para outras formas culturais) como uma vitória inegável da esquerda liberal, se não da esquerda propriamente dita, o prefácio ao livro já deixava claro seu próprio compromisso com "tentar articular e mesmo viver uma crítica não apenas dos excessos do capitalismo em sua forma atual, mas do capitalismo em si” (Ibidem, p. ix).

Mas voltemos ao paradigma crítico, regido pelo desejo de intervir na cultura, e não apenas analisá-la. Seu modo de intervenção, como já mencionei, teria passado pela educação da sensibilidade, com vistas a desenvolver modos alternativos, "mais profundos" ou mesmo mais radicais de vida. Na avaliação de North, essa educação estética não precisaria de modo algum ficar restrita ao cultivo do chamado bom gosto, nem preocupada com hierarquias relativas ao valor das obras, como foi em geral o que aconteceu no período de maior força do paradigma crítico. Contudo, para North, essa tendência assumidamente elitista teria se devido muito mais ao conservadorismo mais ou menos declarado de críticos específicos e então dominantes na academia (os New Critics nos EUA, Leavis na Inglaterra) do que propriamente ao paradigma crítico como um todo. De qualquer forma, para que essa educação da sensibilidade pudesse ser efetivamente cumprida, ela precisaria não permanecer restrita ao espaço institucional da universidade, mas sim circular num espaço público mais amplo. Como resume North, a prática da crítica literária forneceu no mundo anglófono, dos anos 1920 até meados dos 70, não só "uma ponte crucial entre o jornalismo literário de um lado e a pesquisa em literatura do outro", como estabelecia também "os laços mais fortes e explícitos, tanto intelectuais quanto institucionais, com a educação básica - laços que não mais existem sob qualquer forma significativa" (Ibidem, p. 5). É precisamente nesse sentido da perda de uma ligação sólida da academia com o mundo ao redor que a vitória do paradigma historicista-contextualista se alinha à derrota mais ampla da esquerda, cujos efeitos são agora evidentes em qualquer olhada no 
jornal. A análise das culturas através dos textos literários que foram nelas produzidos, distantes ou próximas no tempo e no espaço (O Brasil do século XXI, a Inglaterra do final do XIX), tendeu à especialização com tudo o que ela dá direito e cobra, de bom e de ruim, indo, digamos, da possibilidade de uma compreensão mais afiada do estado da cultura ao uso crescente de jargões teóricos, úteis como atalhos conceituais em argumentos e explicações feitas em ambientes controlados (a sala de aula, a revista acadêmica, o congresso da área), mas verdadeiros empecilhos fora deles - algo que fica claro para qualquer um que tente explicar o que é um focalizador narrativo ou o real lacaniano para uma pessoa (não-acadêmica) real. Como lembra North em sentido mais geral, a utilidade de nossos instrumentos de medição dos rumos da cultura, mediados como são o mais das vezes pela literatura, permanece limitada pelo fato de não termos também "um corpo coerente de técnicas e métodos por meio dos quais mudar essa cultura" (NORTH, 2017, p 12), e de termos deixado de investir nossa energia nesse sentido, principalmente do ponto de vista institucional. Colocada nesses termos, a hegemonia do paradigma historicista-contextualista de análise sem qualquer urgência de intervenção - na sensibilidade coletiva, ao menos - aparece como uma espécie de deserção do espaço público.

3.

O contexto da polêmica de North é o americano (ele é professor de literatura de língua inglesa em Yale), o que evidentemente coloca uma série de ressalvas a sua transposição sem mais para o solo brasileiro. Nossa especialização só alcança graus equivalentes aos de lá em casos pontuais (se tanto), e se o futuro parece agora incerto ou mesmo terrível também nesse sentido, a universidade, tanto por ser pública quanto por conta de sua expansão de outrora, veio sendo consideravelmente mais porosa do que a de lá a diferentes camadas da sociedade. De outro lado, num país marcado por níveis grotescos de analfabetismo como o nosso - mais da metade da população era analfabeta ainda em $1950^{4}$, e os índices nacionais ainda não são (nem nunca foram) muito melhores do que os globais ${ }^{5}$-, falar de um espaço público mediado pela palavra escrita só faz sentido com o uso de algumas (ou várias) aspas. Por conta disso tudo (e haveria outros motivos), não tenho a pretensão nessa fala de qualquer veredicto definitivo da validade do que diz North para o contexto brasileiro - mas tenho cá, mesmo assim, minhas intuições sobre o assunto.

\footnotetext{
${ }^{4}$ Segundo o Mapa do analfabetismo no Brasil, disponível no site do INEP.

${ }^{5}$ Dados disponíveis em: 〈https://ourworldindata.org/literacy〉. Acesso em: 15 out. 2020.
} 
Uma dessas intuições, então, parte do fato de que o argumento de North passa em geral ao largo de desenvolvimentos na própria esfera da arte. Voltando à gravata azul de Picasso: na leitura que Danto faz do caso que ele mesmo inventa, seu sentido seria exclusivamente formal, e diria respeito a questões internas à própria pintura (lembrando: a estreiteza da "metafísica da pincelada" dos expressionistas abstratos), o que me parece estar de acordo com o fechamento geral das artes que começou com as vanguardas, com artistas e escritores criando obras que cada vez mais iam fazendo sentido apenas para seus pares, igualmente imersos na tradição que comentavam - e significando patavina (para dizer o mínimo) para todos os que estamos fora dela, como o pai da criança que diz "até meu filho faz isso". Simplificando muito algo que é na verdade bastante complicado, essa hiperformalização do sentido, que culmina em obras conceituais como a caixa de sabão que Andy Warhol leva para dentro do museu, levou a arte, de um jeito até paradoxal, ao abandono do que Danto chama de suas propriedades estéticas (ou pragmáticas), no sentido muito básico de "predispor na audiência sentimentos de um tipo ou de outro em relação ao que a obra de arte representa" (DANTO, 2015, p. xv). Esgarçando um pouco o paralelo, a especialização e o consequente isolamento aconteceram tanto na academia quanto na própria arte, cada uma em seu ritmo mais ou menos próprio - o que, claro, não deixa de ser também uma tendência geral da sociedade, como se sabe no mínimo desde Weber. Mas, mais do que isso, o resultado curioso é também o de que tanto a academia quanto a arte se afastaram de questões relativas à sensibilidade e, de novo, cada uma a seu modo. Se uma explicação pormenorizada dos motivos dessa dinâmica não caberia nestas páginas (e, provavelmente, nem em minhas capacidades), é possível aqui ao menos arriscar dizer que, não sei bem se como causa ou efeito (ou ambos), a propaganda e a indústria cultural como um todo têm agora algo como o monopólio das técnicas de educação da sensibilidade - o que por si só já aponta para o fato de que a ideia de uma educação da sensibilidade não precisa ir numa direção necessariamente dita elitista (ao contrário, nada é mais inclusivo, se não exatamente democrático, do que o Netflix ou o Youtube).

Mais algumas palavras sobre este último ponto, na tentativa de evitar ainda outros malentendidos. A expressão "indústria cultural” remonta ao célebre capítulo da Dialética do esclarecimento de Adorno e Horkheimer, um texto que se volta, entre diversas outras coisas, também para questões ligadas ao que vim chamando aqui, seguindo North, de "educação da sensibilidade". Em certo momento do ensaio, Adorno e Horheimer escrevem, com verve característica, que "[a] função que o esquematismo kantiano ainda atribuía ao sujeito, a saber, referir de antemão a multiplicidade sensível aos conceitos fundamentais, é tomada ao sujeito pela indústria. O esquematismo é o primeiro serviço prestado por ela ao cliente. (...) Para o 
consumidor, não há nada mais a classificar que não tenha sido antecipado no esquematismo da produção" (ADORNO, 2010, p. 117). O argumento pode parecer um pouco exagerado para nossos olhos de hoje: as próprias categorias que mediam a relação entre entendimento e estímulos sensoriais já teriam sido privatizadas, contaminando de ideologia nossa apreensão mais básica do mundo - o que por sua vez acarretaria sérias consequências para nossa capacidade de imaginação de outros mundos possíveis, que aliás talvez ande em falta. Uma versão bem menos extrema dessa ideia pode ser encontrada num debate televisivo nada acalorado ocorrido em meados dos anos 1950 entre Adorno e Hellmut Becker, na época o presidente das Escolas Superiores de Educação Popular da Alemanha. Após uma série de concordâncias, Becker tenta reformular uma colocação de Adorno, dizendo que "no fundo existe o perigo de os jovens procurarem imaginar o amor, por exemplo, tal como ele é apresentado na tevê, isto é, assumam para relações humanas muito diretas representações estereotipadas antes que eles mesmos as tenham vivido" (Idem, 1995, p. 80-81). Pouco depois, Adorno irá fazer a ressalva necessária de que a existência de um modelo anterior à experiência que acabe em alguma medida por moldá-la nada tem de problemático em si, já que algo semelhante acontecia em outras épocas (e segue acontecendo em menor medida) com o apoio, por exemplo, da literatura. A questão para ele então não diria respeito à transmissão de modelos culturais, mas sim ao fato de que ela passa agora a ser feita em escala industrial e de acordo com sua lógica. Adorno extrapola o meio televisivo, que era o tema do debate, para lembrar que a TV "constitui somente um momento no sistema conjunto da cultura de massa dirigista contemporânea orientada numa perspectiva industrial, a que as pessoas são permanentemente submetidas em qualquer revista, em qualquer banca de jornal, em incontáveis situações da vida, de modo que a modelagem conjunta da consciência e do inconsciente só pode ocorrer por intermédio da totalidade desses veículos de comunicação de massa" (Ibidem, p. 88). Se o conteúdo ideológico difuso transmitido por esse esforço conjunto é, como Adorno formula, o de uma "harmonização" insidiosa passível de ser realizada através da mera comunicação (Ibidem, 1995) (em espírito de "tudo não passava de um mal-entendido", digamos) e dispensando a necessidade de qualquer transformação social mais radical, restaria àquilo da cultura que escapa ao sistema não tanto a apresentação de modelos alternativos quanto o desvelamento do que há de falso em todo o resto. Faltando isso, haveria então só o monopólio tendencial que mencionei há pouco como hipótese.

Mas talvez isso tudo soe ainda exagerado - o que não deixa de ser irônico se levarmos em conta o caso tido por Becker como absurdo de que "as pessoas assistam à tevê antes de serem alfabetizadas" (Ibidem, p. 83), algo que, num mundo com mais smartphones do que 
geladeiras, não tem como agora não soar um pouco tocante. O filósofo Robert Hullot-Kentor, responsável pela elogiada tradução da Teoria estética para o inglês, ajuda a explicar a enorme sensação de distância histórica que separa o diagnóstico de Adorno de nossos dias, no ensaio com o título mais do que apropriado de Em que sentido exatamente a indústria cultural não mais existe (HULLOT-KENTOR, 2008). Segundo Hullot-Kentor, no ensaio de Adorno e Horkheimer está em jogo uma ideia de cultura diferente da concepção dominante de hoje, de conotações antropológicas, no sentido de que ela era então considerada como "tudo aquilo que é mais que a autopreservação" (Ibidem, p. 22). E é só a partir desta ideia hoje tão distante "cultura" aparece nos textos de Adorno sempre no singular, o que é significativo por si só - que a expressão "indústria cultural”, hoje naturalizada e fazendo boa figura ao lado de outras como “indústria hospitalar", pode liberar sua carga de oxímoro. Ou melhor, nas palavras de HullotKentor: “Assim, toda indústria (como entendida por Adorno) permanece até hoje estruturalmente atrelada à autopreservação. A indústria cultural, como produção de cultura por meio da indústria, é o agente por meio do qual tudo aquilo que poderia ir além, e que de fato vai além, da autopreservação da vida é reduzido à violenta luta pela sobrevivência. Assim, a produção de cultura como produção da barbárie é a indústria cultural. ” (HULLOT-KENTOR, Ibidem, p. 22). Distância histórica - mas não necessariamente engano: o cerne do argumento de Hullot-Kentor é justamente o de que não conseguimos sequer captar aquilo de que falavam Adorno e Horkheimer, quanto mais avaliar efetivamente a relação entre seu diagnóstico e a nossa situação... o que, por sua vez, é um dos efeitos possíveis do monopólio tendencial em questão.

Mas, para retomar o argumento e finalmente concluir, volto outra vez a North. Uma de suas propostas é a de recuperar e explorar as ideias sobre a função da crítica literária de I. A. Richards, que foi, como se sabe, um dos inventores da técnica da leitura cerrada tal como a conhecemos hoje, além de ser também muito menos conservador do que Leavis e os New Critics, e de assim funcionar para North como uma espécie de herói da crítica que poderia ter sido e não foi. Trata-se do autor de, entre outros estudos, A prática da crítica literária (RICHARDS, 1997), livro que lida com um experimento inusitado: ao longo de alguns anos como professor em Cambridge na década de 1920, Richards dava aos alunos poemas que iam de Shakespeare aos contemporâneos da época, mas sem identificação de autoria e de data de publicação, e pedia aos alunos que escrevessem suas impressões gerais sobre cada um deles (se tinham gostado ou não, seus motivos para isso etc.). O resultado fica entre óbvio e desconcertante: nesse espírito de enólogos amadores, os alunos apresentavam não só as opiniões mais variadas, como também problemas de compreensão de todo tipo, e em geral um 
desconhecimento mais ou menos completo do funcionamento da mecânica básica da linguagem em verso, e isso a despeito de eventuais conhecimentos sobre a história literária consagrada. Ou seja, em termos simples, alunos de uma universidade de elite britânica que tinham escolhido seguir no estudo da literatura simplesmente não sabiam ler poesia direito. Dividido em três partes, o livro partia de uma (divertidíssima) seleção desses comentários dos alunos - definida por Richards como representativa da "situação atual da cultura" - para depois propor a técnica da leitura cerrada e enfim "preparar o caminho para métodos educacionais mais eficientes do que os que atualmente utilizamos para desenvolver a discriminação e a capacidade de compreender o que ouvimos ou lemos" (RICHARDS, 1997, p. 3). Ou então: a crítica que poderia ter sido - e não foi.

Saltando coisa de cem anos e alguns milhares de quilômetros, chegamos a um país no qual, ao que tudo indica, a falta de discriminação e capacidade de compreender o que ouvimos ou lemos parece ter sido decisiva em nosso salto (nada ornamental) rumo ao colapso de muito mais do que só a crítica literária. A incapacidade de discernir notícias verdadeiras das falsas que circulavam por redes sociais, ao céu aberto do Facebook ou nos subterrâneos do WhatsApp, teve sem dúvida sua importância no voto de muita gente. Ou talvez nem se trate exatamente dessa falta de discernimento básico: parece um pouco de exagero pensar que tantas pessoas acreditaram de fato que, por exemplo, os governos de antes estivessem distribuindo mamadeiras com o bico em formato de pênis pelas creches. Talvez, como na arte de outrora, o que mais importe numa pequena obra-prima de esdrúxulo como essa não seja sua relação com os fatos, mas sim, lembrando a frase de Arthur Danto, sua capacidade de "predispor na audiência sentimentos de um tipo ou de outro" com relação àquilo que é representado: em suma, seu efeito estético. Em um ensaio dedicado às limitações do chamado "método mítico" por trás de A terra devastada, de T. S. Eliot, o crítico Franco Moretti argumenta que a restauração do sentido ao mundo que seria o resultado proposto pelo método em questão só viria a ser realizada plenamente (e em chave muito diversa) pela cultura de massa. A citação é longa, mas vale a pena: "Além do verdadeiro e do falso: os produtos mais típicos da cultura de massa nos levam de volta à proposição que criou, em sua época, a autonomia da arte, mas com a diferença decisiva de que, enquanto o caráter não referencial da literatura era evidente e reconhecido como tal, limitando assim as pretensões e o alcance desse uso específico da linguagem, a cultura de massa, pelo contrário, espalha esse artifício semântico em toda a extensão das atividades culturais, com exceção da ciência e da tecnologia, transformando, assim, a autoreferencialidade do caso limítrofe que costumava ser na práxis normal da comunicação" (MORETTI, 2007, p 273). Com exceção da ciência e da tecnologia: no caso da tecnologia, sim, 
sem dúvida; já no da ciência, talvez não mais, ou nem tanto. E talvez seja hora de também começarmos a pensar sobre isso.

Talvez ainda dê tempo.

\section{Referências}

ADORNO, Theodor W. Televisão e formação. In: . Educação e emancipação. Trad. de Wolfgang Leo Maar. São Paulo: Paz e Terra, 1995, p. 75-95.

ADORNO, Theodor W.; HORKHEIMER, Max. Dialética do esclarecimento: fragmentos filosóficos. Trad. de Guido de Almeida. Rio de Janeiro: Zahar, 2010.

BROWN, Nicholas. Autonomy. Durham, NC: Duke University Press, 2019.

DANTO, Arthur C. A transfiguração do lugar-comum. Trad. de Vera Pereira. São Paulo: Cosac Naify, 2005. 2015. O abuso da beleza. Trad. de Pedro Süssekind. São Paulo: WMF Martins Fontes,

DURÃO, Fabio A. Do texto à obra e outros ensaios. Curitiba: Appris, 2019.

GREENBERG, Clement. Towards a Newer Laokoon. In: . Collected Essays, vol. I. Chicago: Chicago University Press, 1986.

HULLOT-KENTOR, Robert. Em que sentido exatamente a indústria cultural não mais existe. Trad. de Fabio A. Durão. In: DURÃ̃, F. A; ZUIN, A.; VAZ, A. F. A indústria cultural hoje. São Paulo: Boitempo, 2008, p. 17-27.

MORETTI, Franco. De A terra desolada ao paraíso artificial. In: Signos e estilos da modernidade. Trad. de Maria Beatriz de Medina. Rio de Janeiro: Civilização Brasileira, 2007, p. 243-277.

NORTH, Joseph. Literary Criticism - A Concise Political History. Londres; Cambridge, MA: Harvard University Press, 2017.

RICHARDS, I. A. A prática da crítica literária. Trad. de Almiro Pisetta e Lenita Maria Rímoli Esteves. São Paulo: Martins Fontes, 1997.

WALLACE, David Foster. Federer both Flesh and Not. In: Both Flesh and Not: Essays. Londres: Penguin Books, 2012. 